\title{
As relações entre quatro sujeitos - Téo, Fernanda, Salete e Lucas - na telenovela Mulheres apaixonadas
}

\author{
Elaine Aparecida Souto ANTUNES \\ (Universidade de São Paulo)
}

RESUMO: A Rede Globo exibiu sua produção Mulheres apaixonadas em 2003. Esta novela apresentou um painel com várias mulheres expondo seus dramas e conflitos. Uma personagem chamada Fernanda teve um relacionamento com Téo. Quando a filha de Fernanda, Salete, fica muito doente, ela entra em contato com Téo e lhe pede dinheiro. Esse acontecimento será analisado para mostrar como a relação desses sujeitos é apresentada ao público no primeiro capítulo de Mulheres apaixonadas.

PALAVRAS-CHAVE: semiótica; telenovela; mulheres

ABSTRACT: In 2003, a Brazilian TV-Station, Rede Globo, broadcasted a show, Mulheres apaixonadas. This soap opera showed a panel of several women exhibiting their dramas and conflicts. A character named Fernanda had a relationship with Téo. When Fernanda's daughter, Salete, becomes very sick, she calls Téo asking him for some money. This fact will be taken as analysis to show how their relationship in the story of Mulheres apaixonadas is introduced to the audience in its first chapter.

KEYWORDS: semiotics; soap opera; women 
inha pesquisa de mestrado tem como corpus a telenovela Mulheres apaixonadas, por isso, no presente artigo, analiso os efeitos de sentido que envolvem as relações de quatro sujeitos - Téo e seu filho Lucas, Fernanda e sua filha Salete - no transcorrer das cenas de números dezoito, vinte e seis e vinte e sete, do primeiro capítulo dessa novela. Meu objetivo é verificar como esse casal, que durante a novela esconde um segredo, foi apresentado ao público telespectador.

$\mathrm{Na}$ cena dezoito, Téo está conversando com seu filho Lucas pelo celular, mas começa a chover e ele precisa desligar o seu telefone (F 01). Essa chuva interrompe o percurso tranqüilo que o personagem estava fazendo, porém não tira dele o bom humor, tanto que ele vê uma garota voltando da praia e faz uma brincadeira, uma piadinha ( $\mathrm{F}$ $02,03,04)$.

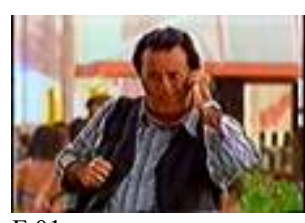

F 01

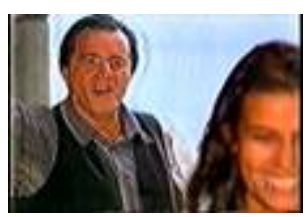

F 03

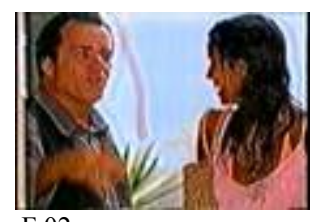

F 02

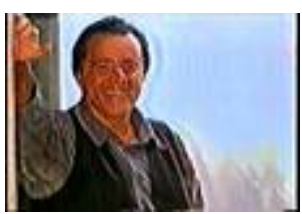

F 04

Téo: - Perdeu a praia gatinha!

Moça: - Falta de sorte, né!

Téo: - É chuva de verão só pra refrescar, mas já já eu vou mandar parar só pra você voltar pra praia!

Durante essa conversa, percebemos que Téo está totalmente descontraído. Seus gestos e seu tom de voz colaboram para construir esse efeito de sentido de descontração. Porém, logo em seguida a narrativa se altera com o aparecimento de Fernanda (F 05). Agora, a chuva está mais forte (F 06) e de dentro de um táxi a moça o chama. Imediatamente ele muda de fisionomia e fica irritado (F 07, 08, 09). Ele não quer falar com ela, mas Fernanda é insistente e agora, num tom de voz alterado, diz "Dois minutinho, pô!" (F10) Ele está visivelmente contrariado, contudo se aproxima do táxi e acaba entrando no carro (F 11, 12, 13, 14). 


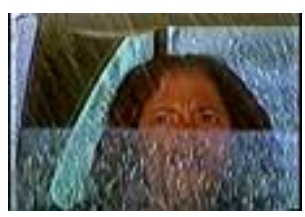

F 05

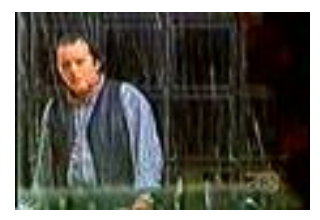

F 06

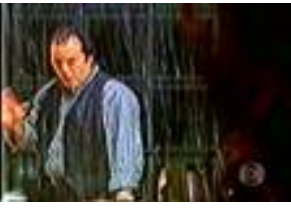

F 09

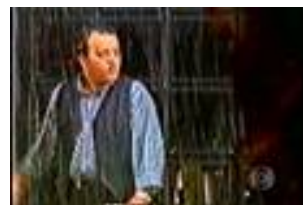

F 12

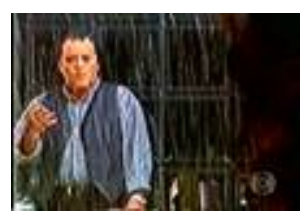

F 07

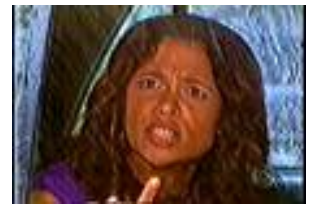

F 10

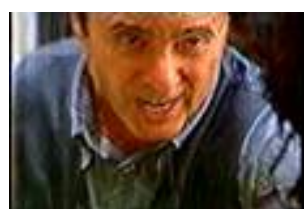

F 13

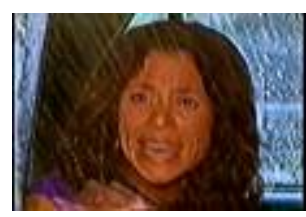

F 08

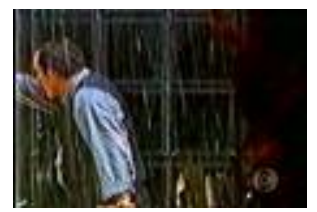

F 11

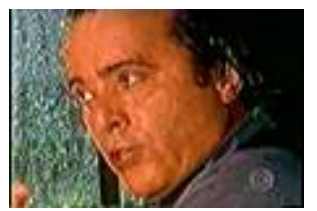

F 14

Essa seqüência de imagens mostra uma transformação no estado passional do personagem Téo; ele estava tranqüilo e descontraído, nas primeiras imagens, quando Fernanda aparece, ele automaticamente muda seu comportamento. Essa transformação é percebida pelo público não só pela recusa verbal em falar com a moça, mas também pela sua alteração física. Lembrando, assim, Greimas em Semiótica das paixões:

É pela mediação do corpo que percebe que o mundo transforma-se em sentido - em língua -, que as figuras exteroceptivas interiorizam-se e que a figuratividade pode então ser concebida como modo de pensamento do sujeito (Greimas, 1993:13).

Olhar para Téo é perceber, através do seu corpo e por meio dos seus gestos, sua transfiguração passional, caracterizada por um desejo de não-conjunção com a outra personagem; Observa-se que nela estão investidos valores indesejados para ele. Apresentar Fernanda ao público, juntamente com um personagem (Téo) que se mostra irritado em vê-la, de certa forma, desqualifica e constrói sua imagem como uma mulher que não tem o mesmo prestígio que as outras personagens femininas. Esse fato, junto com outros elementos, posiciona Fernanda fora do mundo dele e criam um efeito de sentido de que a ligação deles é proibida, por isso eles não podem ser vistos juntos. Assim, ela é colocada, no modo do parecer, no papel de amante. Para reformar a carga emocional dessa cena, ocorre um aumento de intensidade graças à maneira com que ele a recebe. A tensão se estende durante todo o tempo em que eles permanecerem juntos. 
Se atentarmos bem, outra maneira de construir a imagem de Fernanda como um sujeito indesejado é a figurativização da chuva forte. Trata-se de uma oposição entre o sol que iluminava o caminho tranqüilo de Téo no calçadão da praia e a chuva que de repente começa a cair, ao mesmo tempo em que Fernanda aparece. A câmera focaliza a chuva forte do lado de fora do carro, enquanto ele irritadíssimo declara que eles tinham um acordo e ela rompeu esse acordo ao aparecer sem avisar. Ao falar isso, Téo demonstra que existia um contrato fiduciário e acreditava que ela nunca o quebraria, o fato de ela não ter honrado o trato deles é o motivo de tanta irritação.

Téo: - Que que é isso, a gente tinha combinado que você nunca iria aparecer assim sem avisar e quase na esquina da minha casa!

Essa frase do personagem assinala que Fernanda não faz parte da sua vida e do seu mundo. Logo, constrói sua imagem como alguém que não pode de forma alguma ser vista com ele. Nesse instante, Téo está modalizado pelo não- querer e não- poder estar junto dela. Ele deixa claro por meio de suas atitudes e palavras que está desagradado em vê-la $(F 15,16,17)$. Como já salientei anteriormente, ele diz que existia um contrato entre eles, e o fato de ela ter rompido esse acordo é um dos fatores que alteram seu estado passional. Dizem Fontanille e Zilberberg:

O nascimento e a morte de uma paixão - muitas vezes tão incompreensíveis um quanto outro - tomariam a forma, do ponto de vista do sujeito, de crises fiduciárias, tanto umas quanto as outras assegurando ou não a continuidade passional (2001:277).

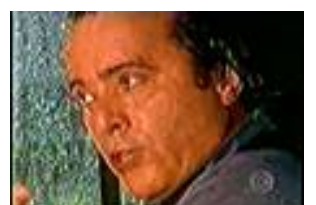

F 15

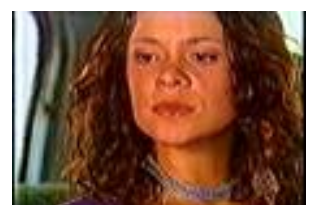

F 16

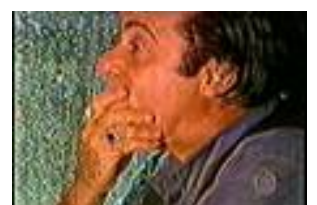

F 17

Os elementos figurativos e lingüísticos que se articulam até o presente instante determinam a posição que essa mulher ocupa para Téo, ou seja, o telespectador fica com a sensação de que os dois têm uma relação proibida, um romance. Fernanda aparece no enunciado como alguém que precisa estar escondida, portanto ela é apresentada no papel de amante. Não é possível determinar se ela é ou foi amante dele, mas está claro que esse é o efeito de sentido que se pretende criar para o telespectador.

A conversa continua com ela afirmando que está com um problema e Téo argumenta que ela não está com um problema, mas ao contrário "Você é um problema, o problema!". O artigo definido "o" na frente do substantivo "problema" e o tom de voz de Téo novamente enfatizam que ele vê Fernanda como uma pessoa indesejada e que ela não lhe traz coisas boas, representando, portanto, um perigo. Mesmo assim, ele pergunta de quanto dinheiro ela está precisando (F 18). 


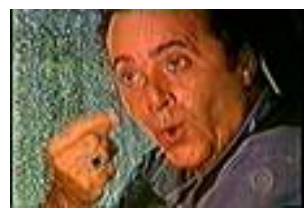

F 18

Ela responde dizendo: "Olha! Olha!" e sinalizando para o lado mostra sua filha doente enrolada em um cobertor (F 19). Quando Téo vê a menina sua fisionomia se altera e presenciamos a preocupação dele com a criança (F 20). Então, ele questiona Fernanda (F 21):

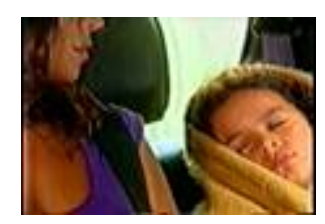

F 19

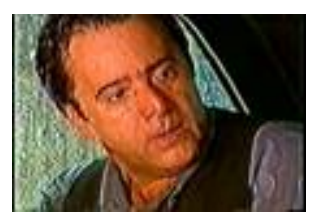

F 20

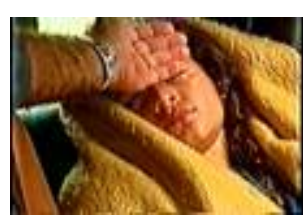

F 21

Téo: - O que essa menina está fazendo aqui dessa maneira? Salete, Salete o que aconteceu com você?

Fernanda: - Tá doente, tá assim há dois dias. Tosse, dor de cabeça. Tô faltando no serviço por causa disso, Téo!

Téo: - Essa menina tá fervendo!

Durante essa conversa notamos nitidamente que ele se preocupa com a garotinha, ele expressa isso fisicamente, na sua fisionomia; gestualmente, colocando a mão em Salete para verificar se ela está com febre; e verbalmente, questionando Fernanda. Essa preocupação desperta no telespectador uma série de pressuposições, como por exemplo: a menina deve ser filha dele e por esse motivo ele está dando tanta atenção para Fernanda.

Ele demonstra sentir-se tão responsável pela menina que Fernanda lhe pede mil reais para comprar remédio e ir ao supermercado, e ele apesar de um certo descontentamento, por estar sendo aparentemente explorado, não nega o pedido e lhe dá o dinheiro. Eles vão até um caixa eletrônico e Téo desce para pegar o dinheiro; enquanto isso, Fernanda desabafa com o taxista (F 22, 23, 24):

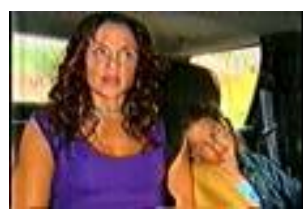

F 22

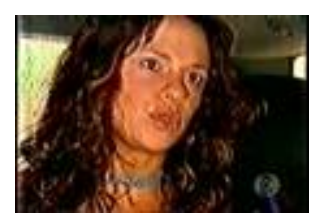

F 23

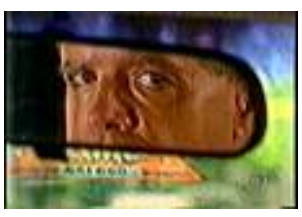

F 24 
Fernanda: - Tá tudo tão caro, né moço: remédios, comida... Com filho então, não dá pra agüentar! Sabe que o miserável do dono do apartamento onde eu moro tá atrás de mim pra aumentar o aluguel, aumentar o aluguel! Aumentar não, ele quer dobrar o aluguel! O senhor já viu uma coisa assim? Me atormenta todo dia. E olha que é um apartamento pequeno, deste tamanho, em Copacabana. Pó dobrar o aluguel!

Essa fala da personagem marca no enunciado duas posições: Téo/ rico vs Fernanda/ pobre, temos, então, uma tensão entre os dois sujeitos pelas seguintes oposições:

\begin{tabular}{|l|l|l|}
\hline Nível narrativo & $\begin{array}{l}\mathrm{S} \cap \text { Ov (estabilidade } \\
\text { financeira) }\end{array}$ & $\begin{array}{l}\text { S U Ov (estabilidade } \\
\text { financeira) }\end{array}$ \\
\hline Nível discursivo & $\begin{array}{l}\text { Modos de figurativização } \\
\text { da riqueza }\end{array}$ & $\begin{array}{l}\text { Modos de } \\
\text { figurativização da } \\
\text { pobreza }\end{array}$ \\
\hline & $\begin{array}{l}\text { Téo } \\
\text { Lucas } \\
\text { Saúde } \\
\text { Dinheiro }\end{array}$ & $\begin{array}{l}\text { Fernanda } \\
\text { Salete } \\
\text { Doença } \\
\text { Aluguel/ despejo }\end{array}$ \\
\hline
\end{tabular}

O telespectador, algumas cenas antes, soube que Téo irá para a fazenda de helicóptero, enquanto a moça que lhe pede ajuda financeira, nesse momento, nem consegue pagar o aluguel do apartamento onde mora e nem mesmo tem dinheiro para comprar os remédios da filha. Esses fatos constroem um efeito de distanciamento, separando assim o mundo desses dois sujeitos.

Depois de entregar o dinheiro para Fernanda, Téo pergunta se ela está cuidando bem da menina; enquanto ela responde que sim, ele se vira para Salete e diz (F 25):

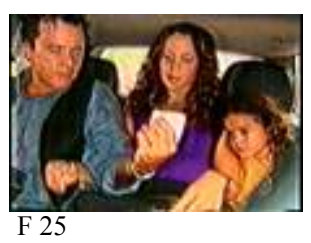

Téo: - Salete, titio aqui semana que vem vai te vê e eu vou levar uma boneca bem bonita pra você. Aí a gente sai um pouquinho, vamos tomar um sorvete, tá bom? Pode esperar.

Com essa fala, Téo promete visitá-la e mais uma vez demonstra que tem apego e preocupação com relação à menina. Ou seja, será que ele é o pai de Salete? Essa pergunta fica sem resposta, contudo ele assumiu um compromisso moral com a 
garotinha, o que significa que eles se encontrarão, porém, ele não se colocou como pai, pois carinhosamente usou a palavra "titio".

Quando Téo termina de falar com Salete, Fernanda pergunta sobre o Lucas e conta que recortou a foto deles dois, que foi publicada em uma revista, e colocou em um porta-retratos. Desse fato surgem uma outra pergunta para a qual não há resposta: Por que o interesse de Fernanda em Lucas? Depreende-se essa questão na maneira carinhosa dela falar sobre o menino, pois ela deixa entrever, sutilmente, um afeto por Lucas.

Em resumo, a cena dezoito descreve a transformação do sujeito Fernanda, que estava disjunto do poder cuidar bem da sua filha e graças à ajuda de Téo entra em conjunção com o poder-fazer. Está nítido que ele não se sentiu confortável em encontrála. Mesmo assim, não teve coragem de lhe negar ajuda. Quando o percurso narrativo é executado por completo, Téo quer retomar seu caminho. Fernanda lhe oferece carona argumentando que está chovendo, então ele diz: "Perto dessa chuva você é uma tempestade!".

A figura da tempestade como último elemento caracterizador dessa mulher lhe atribui e intensifica um traço de negatividade, ajudando, dessa forma, a reforçar a idéia que se desenvolveu ao longo dessa cena. A chuva, que não pára em nenhum momento, caracteriza Fernanda como um problema para ele. Na enunciação e no enunciado fica claro que ela é um sujeito com quem ele não deseja estar conjunto. Mas a figura da menina representa o laço que os une, aparentemente é essa criança que estabelece o vínculo entre eles.

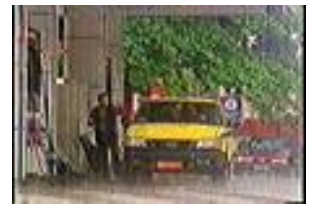

F 26

Quando Téo sai do carro, a câmera o focaliza parado e a chuva está muito forte (F 26). Essa imagem é apreendida durante alguns instantes para, mais uma vez, reforçar a isotopia que permeou esse texto, em que a tempestade é uma forma metafórica e intensamente forte de representação da posição de Fernanda, como alguém que oferece perigo para Téo, pois ele já foi apresentado em outros momentos do primeiro capítulo como um homem que tem esposa e filho.

$\mathrm{Na}$ cena vinte e seis vemos Téo e Lucas conversando no banheiro, enquanto Téo faz a barba. Ao terminar de se barbear, os dois tomam banho juntos. Aparentemente essa cena não tem nada de muito especial, expõe apenas a relação entre pai e filho. No entanto, a cena vinte e sete, que vem logo em seguida, mostra Fernanda e Salete chegando em casa.

Colocando as duas cenas uma após a outra se estabelece um paralelo entre as duas. Pois, relembrando que a imagem de Téo se constrói a partir da riqueza e a imagem de Fernanda se respalda pela pobreza, agora teremos no enunciado os espaços onde cada um está inserido, juntamente com seus filhos. 
Na cena vinte e seis, o telespectador vê apenas o banheiro do apartamento de Téo. Porém, nesse espaço temos as figuras das toalhas brancas, uma grande banheira, uma parede de tijolos de vidro, ducha e um grande espaço. Essas figuras caracterizam esse ambiente como um lugar gostoso, uma vez que sendo o banheiro grande, espaçoso, limpo e agradável permite aos dois ficarem ali desenvolvendo um agradável diálogo ( $\mathrm{F}$ $27,28,29)$.

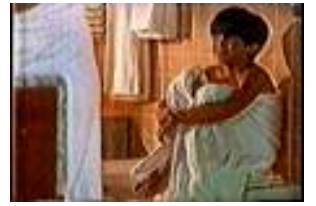

F 27

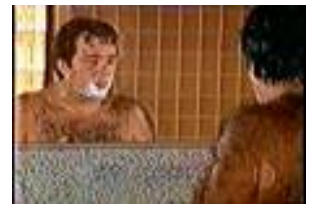

F 28

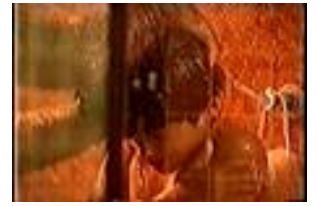

F 29

A conversa entre pai e filho gira em torno de um assunto banal, mas possibilita ao telespectador perceber a existência de uma relação equilibrada e uma forte amizade entre os dois. Ao mesmo tempo que estabelece o efeito de sentido de harmonia familiar, pois tanto o pai como o filho estão alegres e felizes conversando e terminam a história dessa cena tomando banho juntos.

Em contrapartida, na cena vinte e sete as coisas são diferentes. O telespectador vê Fernanda chegando em casa com a filha doente (F 30). Em seguida, Inês, a mãe dela, entra na sala $(31,32)$. Imediatamente, Fernanda lhe pede para ficar um pouco com a menina para ela ir à farmácia, mas Inês se recusa e alega que precisa ir embora porque toda hora chove e ela não pode se atrasar.

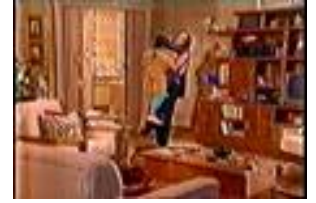

F 30

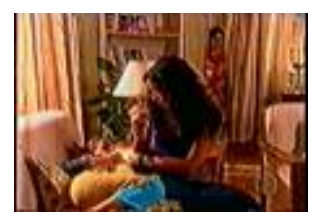

F 31

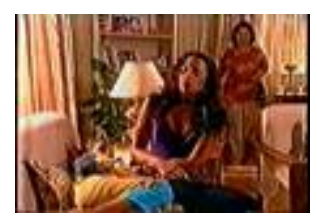

F 32

Nesse instante, Inês se direciona para a porta e a câmera focaliza Fernanda que acabou ficando de costas para sua mãe. Inês pára na porta, olha para a filha que está de costas e pergunta onde ela conseguiu dinheiro (F 33, 34).

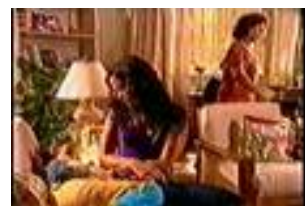

F 33

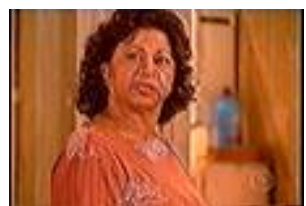

F 34

Inês: - Onde é que você conseguiu o dinheiro, fez vale no serviço outra vez? Assim, no fim do mês não vai ter nada pra receber. 
Fernanda: - O Téo, O Téo me deu mil reais. Inês: - Você tem mais sorte do que merece.

Quando Inês faz a primeira pergunta, visualizamos no semblante de Fernanda (F 35) todo seu descontentamento. Esse descontentamento se mostra na maneira com que ela levanta a cabeça (F36), na forma de mexer os ombros e na sua fisionomia ao virar de frente para a mãe (F 37, 38, 39, 40). Contudo, Fernanda não é estúpida com a mãe e responde a sua pergunta. Inês, então, diz que "Fernanda tem mais sorte do que merece!", esse comentário mostra que Inês não tem carinho pela fillha e não está preocupada nem com Fernanda nem com a neta. A enunciação da mãe também evidencia todo seu desafeto e sua falta de consideração com relação a Fernanda.

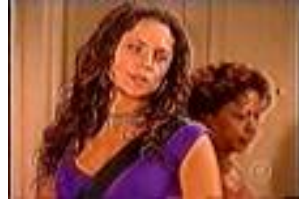

F 35

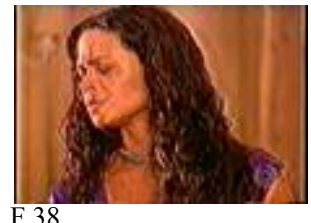

F 38

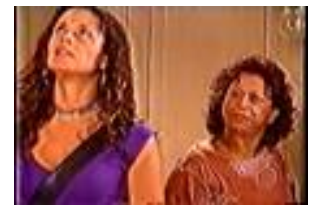

F 36

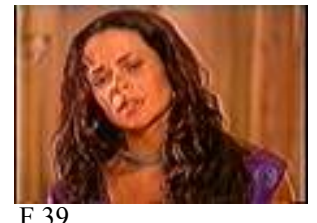

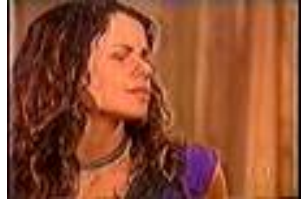

F 37

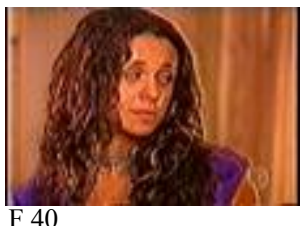

Antes de sair, Inês também diz que o dono do apartamento esteve lá cobrando o aluguel e se a filha for despejada não tem lugar na casa dela. Ao sair, Inês pára na porta e olha para Fernanda como quem quer dizer mais alguma coisa, porém não fala nada. Inês finalmente fecha a porta e vai embora. Essa cena marca no enunciado a desestruturação familiar de Fernanda. $\mathrm{O}$ enunciador cria o efeito de sentido de que Fernanda é uma mulher sozinha, tem uma filha para criar e seu único apoio é Téo.

Logo que Inês sai, Fernanda conversa com Salete e com uma voz muito carinhosa diz à menina que ela ficará boa, irá crescer e será uma pessoa muito feliz. Enquanto Fernanda conversa com Salete, a câmera se movimenta e mostra o portaretrato com a foto de Téo e seu filho Lucas.

Finalizando a história deles, desenvolve-se um jogo de câmeras que enfatiza a ligação entre esses quatro sujeitos, pois ao mesmo tempo em que Fernanda está conversando com a filha o observador apreende a imagem das duas tendo ao meio a presença de Téo no porta retrato (F 41). Nesse instante, o texto privilegia a relação das duas com ele, pois a cabeça de Fernanda cobre a imagem de Lucas. Depois de apreender e se fixar nessa posição, a câmera se movimenta e o observador apreende Téo, Lucas e Fernanda. Agora, a imagem de Salete está encoberta pela mão de Fernanda (42). 


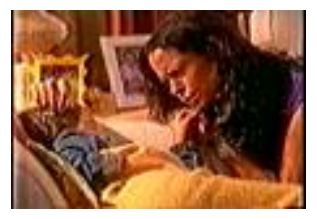

F 41

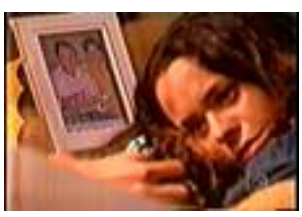

F 42

Essa movimentação da câmera cria o efeito de que existe uma ligação de Téo com as duas, mas também existe o inverso, uma ligação de Fernanda com Téo e Lucas. Essas imagens encerram a apresentação, no primeiro capítulo, desses quatro sujeitos, intensificando a idéia de que existe uma ligação entre eles, porém, fica implícito para quem estiver interessado ou curioso, o convite de assistir à novela e descobrir o segredo que os une.

\section{REFERÊNCIAS BIBLIOGRÁFICAS}

BARROS, Diana L. P. Teoria do discurso - fundamentos semióticos. 3 ed. São Paulo: Humanitas, 2002.

Teoria semiótica do texto. 4ed. São Paulo: Ática, 2003.

FONTANILLE, Jacques \& ZILBERBERG, Claude. Tensão e significação. Tradução de Ivã carlos Lopes et alii. São Paulo: Humanitas, 2001.

GREIMAS, Álgidas Julien \& COURTÉS, Joseph. Dicionário de semiótica. Tradução de Alceu Dias Lima et alii. São Paulo: Cultrix, 1983.

GREIMAS, Algirdas Julien \& FONTANILLE, Jacques. Semiótica das paixões. Tradução de Maria José R. Coracini. São Paulo: Ática, 1993.

Como citar este artigo:

ANTUNES, Elaine Aparecida Souto. As relações entre quatro sujeitos - Téo, Fernanda, Salete e Lucas - na telenovela Mulheres apaixonadas. Estudos Semióticos. [online] Disponível na Internet via WWW.URL: http://www.fflch.usp.br/dl/semiotica/es. Editor Peter Dietrich. Número 4, São Paulo, 2008. Acesso em "dia/mês/ano". 